\title{
Application of Three Electrical Resistivity Arrays to Evaluate Resolution Capacity of Fractured Zones at Apatara Farms, Iwo, Osun State, Nigeria
}

\section{*11 ADEOTI, LUKUMON; ${ }^{1}$ AFOLABI, O.SEUN; ${ }^{1}$ OJO, O.ADEBAYO; ${ }^{1}$ ISHOLA, S.KEHINDE}

\author{
${ }^{a}$ Department of Geosciences, Faculty of Science, University of Lagos, Lagos, Nigeria \\ Corresponding Author: lukuade@yahoo.com samfolbs@yahoo.com,ojo.adebayo.oluwaseun@gmail.com, saidisho@yahoo.co.uk \\ *Tel.: +2348034739175 E-mail address: lukuade@yahoo.com, ladeoti@unilag.edu.ng
}

\begin{abstract}
The study applied three different electrical resistivity arrays (Wenner, dipole-dipole, and Pole-dipole) based on their resolution capacity to delineate fractured zones at Apatara Farm in Iwo, Osun State, Nigeria. Theoretical apparent resistivity data were computed for each model and contaminated with 5\% Gaussian noise as a further concession to real field conditions. The simulated results revealed that the Wenner array gave the least error in trying to reconstruct the true model when the fractured zone is placed near the subsurface. However, when the fractured zone is placed at a depth beyond $5 \mathrm{~m}$, the Dipole-Dipole array gave a better resolution than Pole-Dipole and Wenner array in decreasing order of resolution. The study further revealed that the Wenner array is less susceptible to edge effect at shallow depth while Dipole-dipole is more susceptible to edge effect at deeper depth followed by the Pole-dipole array. 2D electrical resistivity field measurements were carried out to confirm the results of the numerical simulation in the same field using the same parameters. The inverted resistivity images showed that the fractured zones are well delineated by the Dipole-dipole and Pole-dipole arrays but poorly resolved by the Wenner array. The study has demonstrated the usefulness of numerical modelling for imaging of fractured zone necessary for hydrogeological purpose and through modelling, the user has unlimited power to image or simulate a real-world scenario seamlessly before carrying out the actual field survey. (C) JASEM
\end{abstract}

https://dx.doi.org/10.4314/jasem.v21i6.36

Keywords: Electrical resistivity array; fractured zones; finite element method; 2-D models; resolution, mean absolute error

Ambiguity in the interpretation of electrical resistivity dataset as well as other geophysical datasets can be reduced by numerical modelling. This allows one to exploit information of variable value from experience. For example, available well log information can be used to formulate a model, calculate the expected electrical resistivity responses, and subsequently design an efficient field survey to test the hypothesis. Alternatively, one could iteratively adjust a geologic model until the theoretical results fit the existing field measurements (Ojo and Olorunfemi, 2013). For example, the detectability of various two-dimensional earth models using multi-electrode systems in a noisy environment has been studied by (Sandor et al., 2011; Szalai et al., 2014). Such models are representative of fractured zones which are discontinuities in crystalline basement rocks generated by tectonic forces or intrusion of magmatic bodies (George et al., 2013). Hydrologically, they are regarded as structures favourable for the accumulation of groundwater in the subsurface. To image these structures, the Electrical Resistivity Tomography (ERT) method has been used successfully overtime and has proven to be a valuable geophysical tool for solving environmental, engineering and groundwater problems (Francese et al., 2009). Asides, mapping of fractured zone is also important for civil engineering developments (Sunmonu and Alagbe, 2013; Alagbe et al., 2013).

To obtain a reliable and high resolution geoelectric model of the subsurface, an appropriate electrode array must be adopted for the data acquisition to ensure maximum anomaly information, high signal to noise ratio and reasonable data coverage (Loke, 1999; Okpoli, 2013). The appropriate electrode array can be determined and an idea of the anomaly responses can be obtained at the planning stage of the survey using forward modelling rather than trial by error on the field. The usefulness of this was demonstrated by (Xianjin and Lagmanson, 1999) for mapping horizontal and vertical conductor using different electrode arrays. Recently, the use of nonconventional electrode array such as the quasi null arrays has been carried out by (Szalai et al., 2015). However, their practicality and limited knowledge of data interpretation restricted their use. This necessitated further investigation into the use of conventional electrode configuration such as Wenner, Dipole-Dipole and Pole Dipole arrays.

Therefore, in this study, we investigated the resolution capacity of these three conventional electrode arrays to delineate fractured zones at Apatara Farms, Iwo, Osun state using finite element Method (FEM) modelling approach. 


\section{MATERIALS AND METHODS}

Study area: Apatara Farms (Fig.1) is located in Iwo town, Osun State which is in South-Western Nigeria. It lies between latitudes $6^{\circ} 50^{\prime} \mathrm{N}$ and $8^{\circ} 10^{\prime} \mathrm{N}$ and longitudes $4^{\circ} 00^{\prime} \mathrm{E}$ and $5^{\circ} 10^{\prime} \mathrm{E}$. The prevailing climate is distinctly tropical with four climatic seasons (Iloeje, 1976). These include the: long dry or harmattan season (November - March); long wet season (March - July); short dry season (JulyAugust) and short wet season (August - November). Geologically, Osun State is underlain by Precambrian rocks of the basement complex of Nigeria. Several varieties of these rocks possess appreciable degrees of economic mineralization. It has been reported that deep weathering profiles, erosion surfaces and alluvial deposits have accumulated important mineral deposits such as Laterites, Talc and Gold in stream sediments (Ajeigbe et al., 2014).

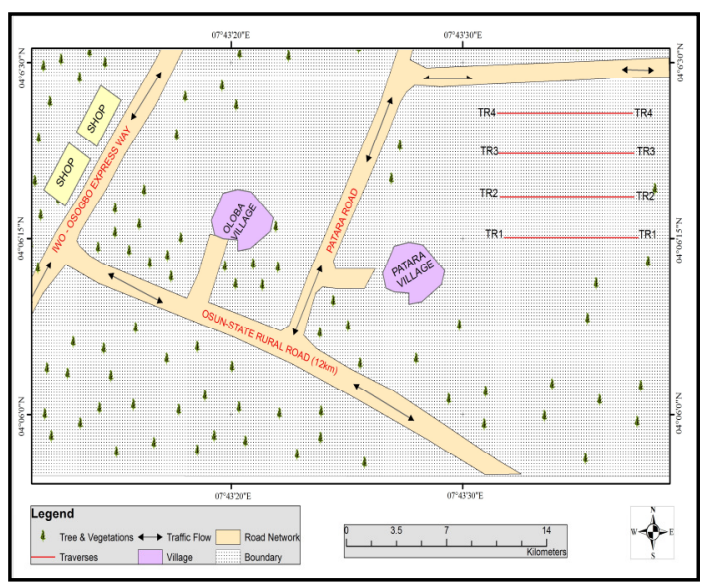

Fig 1: Base map of the study area

Data Acquisition: In order to achieve the objectives of this study, the methodology was grouped into two: the synthetic modelling and real field collection.

Numerical modelling :The governing equation for boundary value related to the Direct Current (DC) resistivity forward problem can be expressed by the equation of continuity considering the mixed boundary condition given by Eq.(1) (Rücker, 2011)

$$
\nabla \cdot(\sigma \nabla u)=-\nabla \cdot j \text { in } \Omega \subset \mathbb{R}^{3}
$$

where $\sigma(x, y, z)$ is the conductivity distribution in the ground, $J$ is the source current density and " $u$ " is the electrical potential. Solving the forward problem requires the computation of the theoretical response for a given set of input model parameters, using the appropriate equations that relate the model to the data.

The fundamental FEM principle provides the approximated solution $\mathrm{U}_{\mathrm{h}}$ belonging to $\mathrm{N}$ discrete points (nodes) within the domain. This can be solved for a set of appropriate weighting functions $w$.

$$
\begin{aligned}
& U \cong U_{h}=\sum_{i=1}^{N} N_{i} U_{h i} \ldots . .(2) \\
& \int_{\Omega} \sigma \nabla w \nabla u d \Omega+\int_{\partial \Omega_{I}} \sigma w \frac{\partial u}{\partial n} d \partial \Omega=\int_{\Omega} W \nabla \cdot j \mathrm{~d} \Omega
\end{aligned}
$$

By applying the FEM approximation rule given by Eq. (2) to the weak formulation given by Eq.(3), and determining the unknown weighting function using the Galekin's criterion $\left(\mathrm{w}_{\mathrm{j}}=\mathrm{N}_{\mathrm{j}}\right)$ (Zienkiewicz, 1977), the FEM approximation for the DC resistivity forward problem can be obtained as stated in Eq.(4).

$\sum_{i=1}^{N} U_{k i}\left(\int \sigma \nabla N_{j} \nabla N_{i} d \Omega+\int_{\partial \Omega i} \sigma \alpha N_{j} N_{i} d \partial \Omega\right)=\int_{\Omega} N_{j} \nabla j d \Omega$

..... (4)

With $\mathrm{j}=1, \ldots \ldots \ldots \mathrm{N}$

The FEM solution presented by Eq. (4) was implemented in the EM2DMODEL software developed at the Korea Institute of Mining and Geology (KIGAM) (Yi et al., 2003) and used for the numerical modelling in this paper. Using the EM2DMODEL software, the theoretical responses for the Wenner (Wen), Dipole-Dipole (Dpdp) and Pole-Dipole (Pdp) electrode arrays over the various 2-D earth models were computed. For the synthetic case, forty-eight generic 2-D earth models of geological relevance were simulated based on the known stratigraphy in basement complex terrain. These include: the top soil, weathered layer, fractured basement and fresh basement. However, only five of these models were reported in this paper. Example of reasonable estimates of the thickness and resistivity values for different lithology in the basement complex is summarized by (Olorunfemi, 2008) and presented in Table 1 where the 2-D resistivity models representative of different lithology in the subsurface were assigned different resistivity values with varying thicknesses and depths of burial. As a further concession to real field conditions, the theoretical apparent resistivity data computed for each model was contaminated with 5\% Gaussian noise (Press et al., 1996). 
Table 1 Geoelectric parameters of a typical basement complex area

\begin{tabular}{lll}
\hline Subsurface Layer & Resistivity $(\mathrm{Ohm}-\mathrm{m})$ & Thickness $(\mathrm{m})$ \\
\hline Topsoil/Laterite & Very variable $1-10,000$ & $\begin{array}{l}\text { Generally }<1.0 \text { but could be as thick as 5.0 in } \\
\text { some places }\end{array}$ \\
Weathered Basement & Usually $<100$ but could be as high as 500 & $\begin{array}{l}\text { It is less than } 30.0 \text { but could be as thick as } \\
60.0 \text { in Schist } \\
\text { Generally }<20.0 \text { but could be as thick as } 40.0 \\
\text { in the same location }\end{array}$ \\
Partly-Weathered/Fractured Basement & Usually $<1000$ & Not Determined \\
Fresh Basement & Usually $>1000$ &
\end{tabular}

Real field data: To further investigate and verify the results of the numerical simulation, a resistivity field survey was carried out over an established fault zone at Apatara Farms, in Iwo, Southwestern part of Nigeria with the same model parameters used in numerical modelling. The two-dimensional (2D) electrical resistivity imaging was carried out along four traverses with each of length $200 \mathrm{~m}$ (Fig. 1). The PASI resistivity meter was used for the data collection. Like in the synthetic cases, the three conventional electrode arrays used were the Wenner, Dipole-Dipole, and Pole-Dipole with electrode spacing in the range of 10 to $60 \mathrm{~m}$.

Data Processing: Both the apparent resistivity measurements for the synthetic and field data were processed in order to obtain the true resistivity distribution using the DIPRO inversion software. It is a $2.5 \mathrm{D}$ inversion code that solves the forward problem of electrical resistivity using either the finite difference method (FDM) or the finite element method (FEM). In this study, however, the 2.5D FEM was used. We determined the edge effect by observing the reflection of the fresh basement resistivity on the inverted resistivity in the first row of the fractured zone in contact with the fresh basement. Evaluation of the reconstructed model accuracy was carried out by estimating the model misfit between the true model and inverted results models. The Root Mean Square (RMS) error, Mean Absolute Error (MAE) and Mean Absolute Percentage Error (MAPE) were estimated using the procedures in Ishola et al., 2014.

\section{RESULTS AND DISCUSSION}

Fig. 2a. shows model consisting of a fractured zone denoted with a resistivity value of $200 \Omega \mathrm{m}$ placed at the surface depth of $0 \mathrm{~m}$ to $15 \mathrm{~m}$. The recovered resistivity value ranges between $159-197 \Omega$ m for the Wenner array, 159-381 $\Omega \mathrm{m}$ for the dipole-dipole array and $155-289 \Omega \mathrm{m}$ for the pole-dipole array. Although the recovered resistivity value for the Wenner array is underestimated, it is closer to the true resistivity value followed by Pole-Dipole while the values obtained from the Dipole-Dipole deviated most. With regard to the geometry of the fractured zone, the image from the Wenner array almost replicates the true geometry of the fractured zone while Dipole-Dipole and Pole-Dipole give a distorted image.

With increasing depth of burial of the fractured zone, for instance at $5 \mathrm{~m}$ depth as shown in Fig. 2b, the inverted resistivity values for the Wenner array, PoleDipole and Dipole-Dipole images are overestimated. The recovered resistivity value ranges between 251 $650 \Omega \mathrm{m}$ for the Wenner array, $119-723 \Omega \mathrm{m}$ for the dipole-dipole array and $160-687 \Omega \mathrm{m}$ for the poledipole array. The dimension of inverted DipoleDipole anomaly is smaller in relation to the actual model follow by Pole-Dipole but the resolution of the image is higher using Wenner array. At this depth, all the investigated arrays give almost the same geometry while at $10 \mathrm{~m}$ and $15 \mathrm{~m}$ depth Figs. $(2 \mathrm{c} \&$ 2d), also the inverted resistivity values for the Wenner array, Pole-Dipole and Dipole-Dipole are mostly overestimated. At this depth range, the inverted resistivity of Dipole-Dipole and Pole-Dipole are closer to that of the true model while Wenner array gives the least resolution with no traces of fractured zone at $15 \mathrm{~m}$ depth. It is also observed that inverted resistivity of fractured zone for dipole-dipole is extremely high at the contact with fresh basement signifying the reflection of basement resistivity. This is tagged as "edge effect". Wenner array is less susceptible to this effect. 

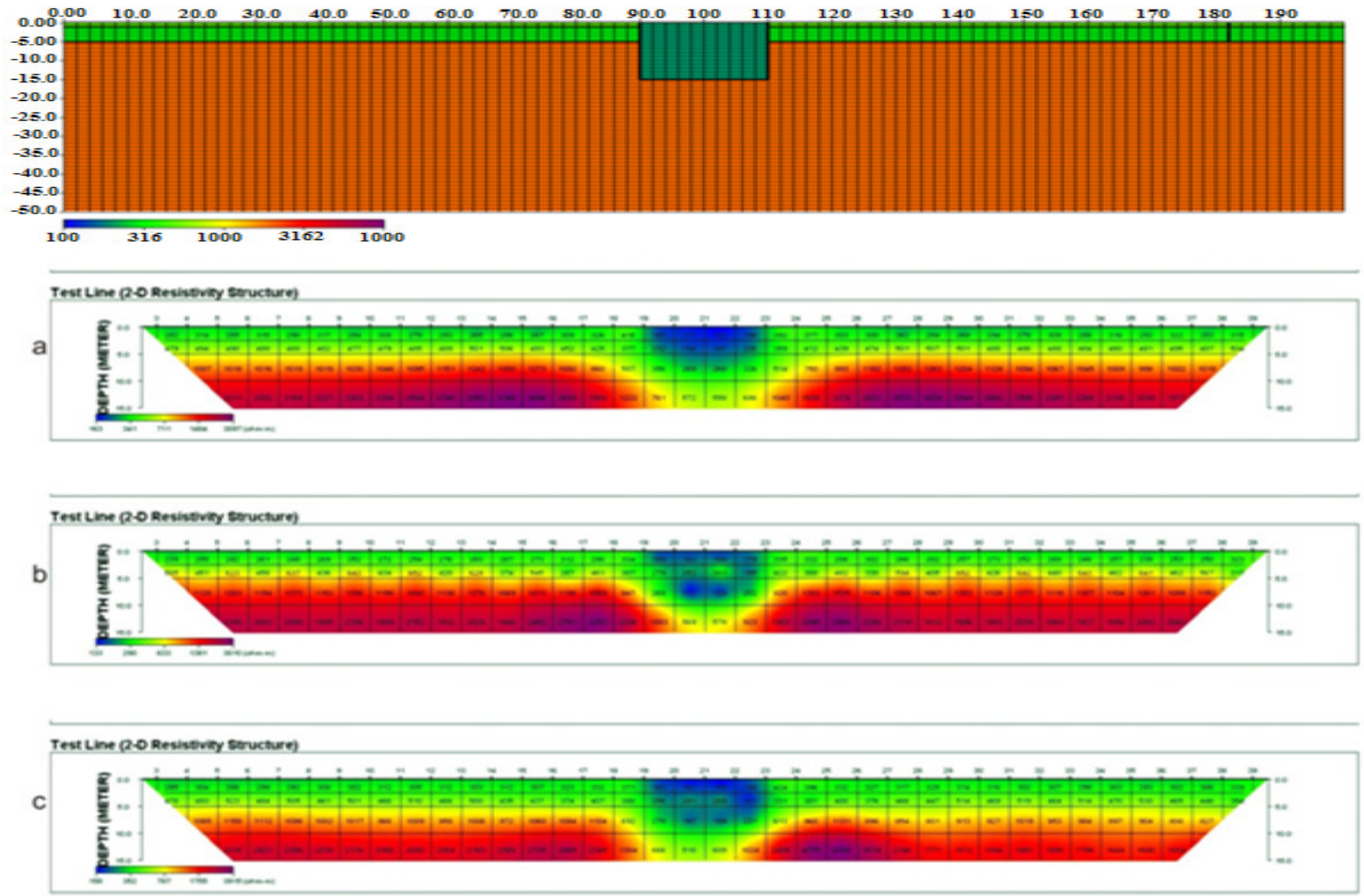

Fig 2a: 2-D generic model with fractured zone of thickness $15 \mathrm{~m}$ located at the surface $(0 \mathrm{~m})$ and $2-\mathrm{D}$ inverted resistivity models for (a) the Wenner (b) dipole-dipole and (c) pole-dipole arrays.
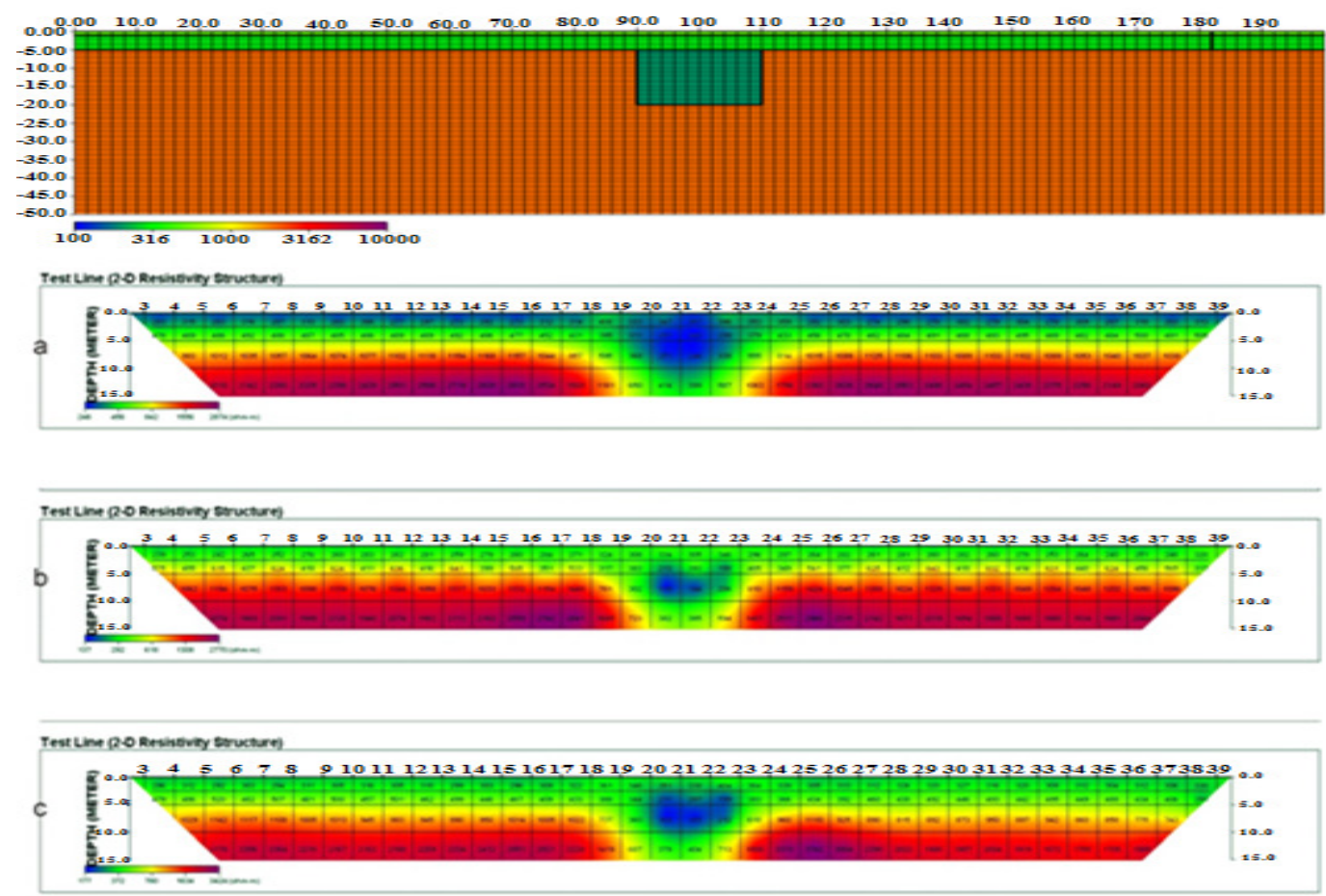

Fig 2b: 2-D generic model with fractured zone of $15 \mathrm{~m}$ thick beneath an overburden thickness of $5 \mathrm{~m}$ and 2-D inverted resistivity models for (a) Wenner (b) dipole-dipole array and (c) pole-dipole arrays. 

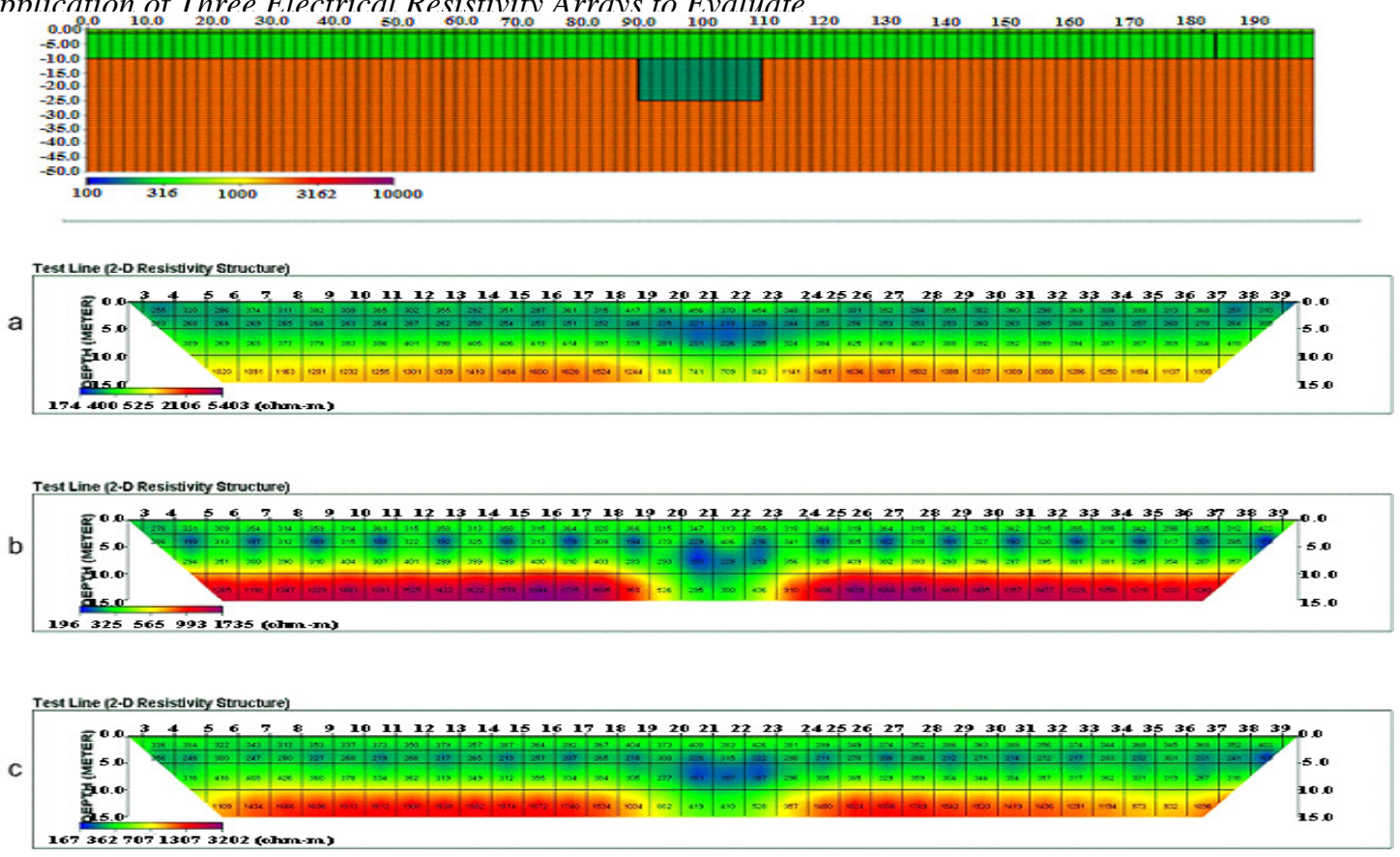

Fig 2c: 2-D generic model with fractured zone of $15 \mathrm{~m}$ thick beneath an overburden layer of thickness of $10 \mathrm{~m}$ and the 2D inverted resistivity models for (a) Wenner (b) dipole-dipole and (c) pole-dipole arrays.

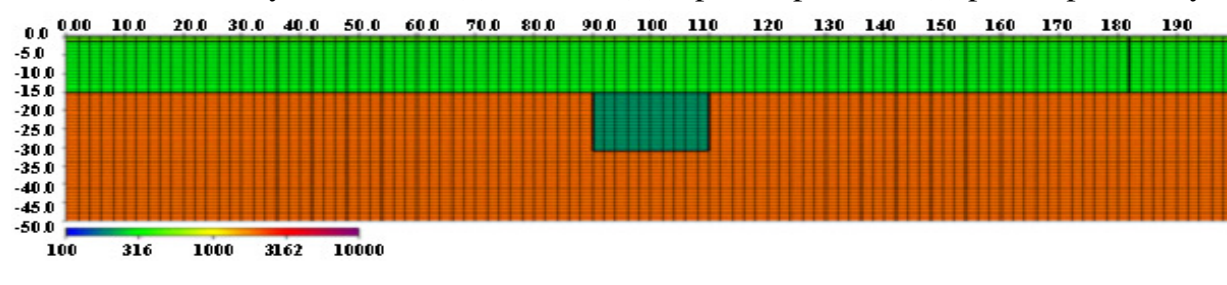

Test Line (2-D Resistivity Structure)
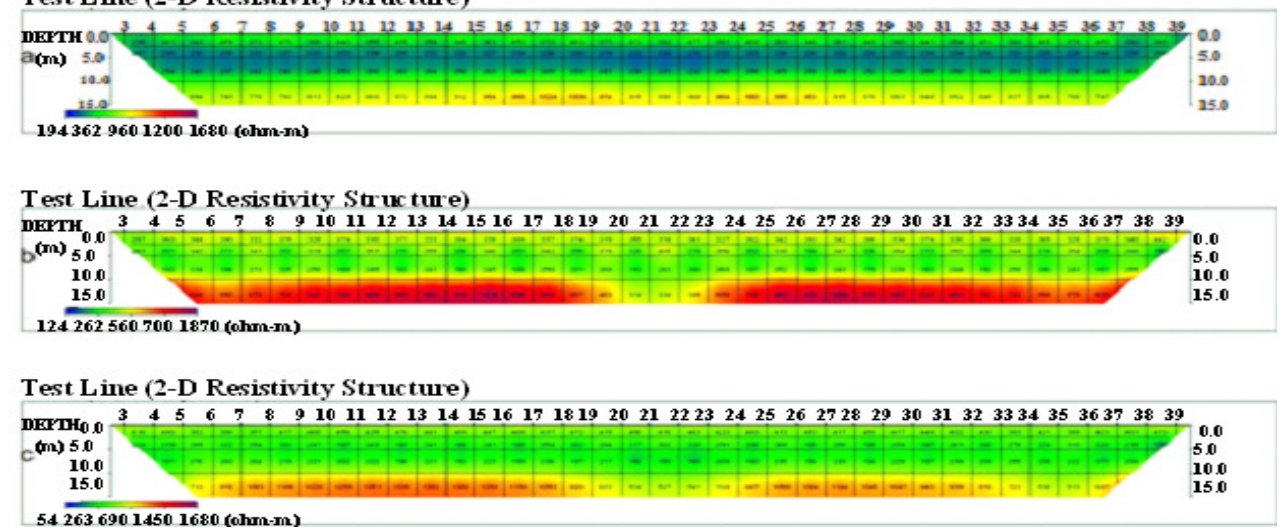

Fig 2d:

2-D generic model with fractured zone of $15 \mathrm{~m}$ thick beneath an overburden layer of thickness of $15 \mathrm{~m}$ and the 2D inverted resistivity models for (a) Wenner (b) dipole-dipole and (c) pole-dipole arrays.

To understand the depth resolution capacity of the three electrode arrays, plots of model misfit against depth are presented in Figs. 3(a-c). Graph of MAPE against depth is represented by solid lines while RMS against depth is represented by broken lines. Also, the model misfits estimated for the fractured zone are presented in Table 2 give RMS in the range of 1.2$7.2 \%$, MAE (0.7- 1.6\%), MAPE $(0.2-1.6 \%)$ for Wenner array.

Dipole-Dipole gives RMS values ranging from 2.535.8\%, MAE 1.5- 6.1\%, and MAPE 0.4- 6.1\% while 
Pole-Dipole gives misfit ranging from 1.2-37.9\% for RMS, MAE between $0.6-6.6 \%$ and MAPE from 0.2$6.6 \%$ when the fractured zone is located at the surface. This implies that the Wenner gives the least model misfit when the fractured zone is placed at the surface followed by Pole-Dipole while DipoleDipole gives the highest misfit. This suggests that the Wenner array is preferable and efficient for delineating near surface fractures. With increasing depth of the fractured zone, the model misfit estimated for each array increases but gives approximately the same value at $5 \mathrm{~m}$ depth. Generally, this indicates a decrease in the resolving power of each electrode array with increasing depth of burial of the fractured zone. However, the misfit error values using the Dipole-Dipole array is smaller than other arrays with increasing depth beyond $5 \mathrm{~m}$ as shown in the Figs. 3(a-c). Thus, the DipoleDipole array is preferable and more reliable for imaging fractures at deeper depth. This verifies the conclusions of (Sandor et al., 2011; Szalai et al., 2014)

Table 2: Summary of inverted resistivity for the models

\begin{tabular}{|c|c|c|c|c|c|c|c|c|c|}
\hline \multirow{2}{*}{$\begin{array}{l}\text { True model } \\
\text { Res. }(\Omega \mathrm{m})\end{array}$} & \multirow[t]{2}{*}{ Thickness(m) } & \multirow{2}{*}{ Depth (m) } & \multirow{2}{*}{$\begin{array}{l}\text { Electrode } \\
\text { Array }\end{array}$} & \multirow{2}{*}{\multicolumn{3}{|c|}{ Inverted Resistivity $(\Omega \mathrm{m})$}} & \multicolumn{3}{|c|}{ Model misfit (\%) } \\
\hline & & & & & & & RMS & MAE & MAPE \\
\hline \multirow{24}{*}{100} & \multirow{24}{*}{20} & \multirow{6}{*}{0} & \multirow{2}{*}{ Wen } & 99 & 88 & 79 & \multirow{2}{*}{3.2} & \multirow{2}{*}{0.5} & \multirow{2}{*}{0.5} \\
\hline & & & & 136 & 107 & 111 & & & \\
\hline & & & \multirow{2}{*}{ Dpdp } & 79 & 77 & 76 & \multirow{2}{*}{14.4} & \multirow{2}{*}{1.7} & \multirow{2}{*}{1.7} \\
\hline & & & & 128 & 167 & 286 & & & \\
\hline & & & \multirow{2}{*}{ Pdp } & 106 & 81 & 71 & \multirow{2}{*}{11.4} & \multirow{2}{*}{1.5} & \multirow{2}{*}{1.5} \\
\hline & & & & 122 & 226 & 193 & & & \\
\hline & & \multirow{6}{*}{5} & \multirow{2}{*}{ Wen } & 255 & 142 & 135 & \multirow{2}{*}{23.3} & \multirow{2}{*}{3.2} & \multirow{2}{*}{3.2} \\
\hline & & & & 367 & 179 & 166 & & & \\
\hline & & & \multirow{2}{*}{ Dpdp } & 188 & 57 & 69 & \multirow{2}{*}{22.6} & \multirow{2}{*}{2.9} & \multirow{2}{*}{2.9} \\
\hline & & & & 382 & 176 & 179 & & & \\
\hline & & & \multirow{2}{*}{ Pdp } & 244 & 80 & 81 & 250 & 34 & 34 \\
\hline & & & & 404 & 197 & 207 & 25.9 & 3.4 & 3.4 \\
\hline & & & Wen & 267 & 233 & 232 & & & \\
\hline & & & Wen & 930 & 780 & 772 & 50.2 & 7.1 & 7.1 \\
\hline & & 10 & Dndn & 310 & 192 & 249 & 228 & 34 & 34 \\
\hline & & 10 & Dpup & 483 & 254 & 260 & 22.0 & 3.4 & 3.4 \\
\hline & & & Pdn & 285 & 183 & 200 & 295 & 42 & 42 \\
\hline & & & Fop & 619 & 367 & 349 & 29.5 & 4.2 & 4.2 \\
\hline & & & Wen & 235 & 214 & 213 & 701 & 113 & 113 \\
\hline & & & wen & 790 & 707 & 702 & 19.1 & 11.5 & 11.5 \\
\hline & & 15 & DPdn & 322 & 228 & 316 & 296 & 42 & 42 \\
\hline & & 15 & DPdp & 318 & 183 & 198 & 29.0 & 4.2 & 4.2 \\
\hline & & & & 239 & 176 & 208 & & & \\
\hline & & & Pdp & 476 & 313 & 298 & 36.2 & 5.5 & 5.5 \\
\hline
\end{tabular}

Table 2: Summary of inverted resistivity for the models cont'd

\begin{tabular}{|c|c|c|c|c|c|c|c|c|c|}
\hline \multirow{2}{*}{$\begin{array}{l}\text { True model } \\
\text { Res. }(\Omega \mathrm{m})\end{array}$} & \multirow[t]{2}{*}{ Thickness(m) } & \multirow[t]{2}{*}{ Depth (m) } & \multirow{2}{*}{$\begin{array}{l}\text { Electrode } \\
\text { Array }\end{array}$} & \multirow{2}{*}{\multicolumn{3}{|c|}{$\begin{array}{l}\text { Inverted Resistivity } \\
(\Omega \mathrm{m})\end{array}$}} & \multicolumn{3}{|c|}{ Model misfit (\%) } \\
\hline & & & & & & & RMS & MAE & MAPE \\
\hline \multirow{24}{*}{200} & \multirow{24}{*}{15} & \multirow{6}{*}{0} & \multirow{2}{*}{ Wen } & 185 & 177 & 159 & \multirow{2}{*}{2.4} & \multirow{2}{*}{0.8} & \multirow{2}{*}{0.4} \\
\hline & & & & 232 & 194 & 197 & & & \\
\hline & & & \multirow{2}{*}{ DPdp } & 159 & 163 & 159 & \multirow{2}{*}{8.8} & \multirow{2}{*}{2.8} & \multirow{2}{*}{1.4} \\
\hline & & & & 279 & 252 & 381 & & & \\
\hline & & & \multirow[t]{2}{*}{ Pdp } & 183 & 162 & 155 & \multirow[t]{2}{*}{5.9} & \multirow[t]{2}{*}{2.2} & \multirow[t]{2}{*}{1.1} \\
\hline & & & & 256 & 281 & 289 & & & \\
\hline & & \multirow{6}{*}{5} & \multirow{2}{*}{ Wen } & 368 & 251 & 244 & \multirow{2}{*}{23.1} & \multirow{2}{*}{7.6} & \multirow{2}{*}{3.8} \\
\hline & & & & 650 & 414 & 399 & & & \\
\hline & & & \multirow{2}{*}{ DPdp } & 302 & 119 & 144 & \multirow{2}{*}{24.5} & \multirow{2}{*}{7.5} & \multirow{2}{*}{3.8} \\
\hline & & & & 723 & 382 & 385 & & & \\
\hline & & & \multirow{2}{*}{ Pdp } & 360 & 160 & 165 & & & \\
\hline & & & & 687 & 379 & 400 & 23.7 & 7.3 & 3.7 \\
\hline & & & Wen & 281 & 231 & 226 & 432 & 120 & 65 \\
\hline & & & wen & 948 & 741 & 709 & 43.2 & 12.9 & 0.3 \\
\hline & & & DPdp & 293 & 180 & 228 & 153 & 44 & 22 \\
\hline & & & & 536 & 295 & 300 & 15.3 & 4.4 & 2.2 \\
\hline & & & & 277 & 181 & 197 & 22.8 & 6.6 & 3.3 \\
\hline & & & Pdp & 662 & 419 & 410 & & & \\
\hline & & & Wer & 247 & 230 & 231 & 51.7 & 15.3 & 7.7 \\
\hline & & & wen & 974 & 915 & 898 & & & \\
\hline & & & DPdp & 269 & 193 & 263 & & & \\
\hline & & 15 & & 463 & 314 & 334 & 13.5 & 4.3 & 2.7 \\
\hline & & & Pdp & 217 & 166 & 190 & & & \\
\hline & & & & 683 & 534 & 527 & 27.5 & 8.0 & 4.0 \\
\hline
\end{tabular}


Table 2: Summary of inverted resistivity for the models cont'd

\begin{tabular}{|c|c|c|c|c|c|c|c|c|c|}
\hline \multirow{2}{*}{$\begin{array}{l}\text { True model } \\
\text { Res. }(\Omega \mathrm{m})\end{array}$} & \multirow[t]{2}{*}{ Thickness $(\mathrm{m})$} & \multirow[t]{2}{*}{ Depth $(\mathrm{m})$} & \multirow{2}{*}{$\begin{array}{l}\text { Electrode } \\
\text { Array }\end{array}$} & \multicolumn{3}{|c|}{ Inverted Resistivity $(\Omega \mathrm{m})$} & \multicolumn{3}{|c|}{ Model misfit (\%) } \\
\hline & & & & & & & RMS & MAE & MAPE \\
\hline \multirow{24}{*}{500} & \multirow{24}{*}{20} & \multirow{6}{*}{0} & \multirow{2}{*}{ Wen } & 191 & 190 & 170 & & & \\
\hline & & & & 230 & 190 & 192 & 1.6 & 0.5 & 0.2 \\
\hline & & & \multirow[t]{2}{*}{ Dpdp } & 162 & 171 & 166 & & & \\
\hline & & & & 280 & 245 & 373 & 7.2 & 2.0 & 1.0 \\
\hline & & & \multirow[t]{2}{*}{ Pdp } & 191 & 177 & 170 & & & \\
\hline & & & & 245 & 259 & 271 & 3.9 & 1.2 & 0.6 \\
\hline & & \multirow{6}{*}{5} & \multirow{2}{*}{ Wen } & 358 & 233 & 224 & & & \\
\hline & & & & 576 & 338 & 324 & 15.9 & 4.3 & 2.1 \\
\hline & & & \multirow{2}{*}{ Dpdp } & 308 & 123 & 152 & & & \\
\hline & & & & 576 & 294 & 298 & 15 & 4.0 & 2.0 \\
\hline & & & \multirow{2}{*}{ Pdp } & 361 & 153 & 157 & & & \\
\hline & & & & 605 & 306 & 308 & 16.5 & 5.4 & 2.2 \\
\hline & & \multirow{6}{*}{10} & \multirow[t]{2}{*}{ Wen } & 267 & 233 & 232 & & & \\
\hline & & & & 930 & 780 & 772 & 38.8 & 11.1 & 5.0 \\
\hline & & & \multirow[t]{2}{*}{ Dpdp } & 310 & 192 & 249 & & & \\
\hline & & & & 483 & 254 & 260 & 11.2 & 2.8 & 1.4 \\
\hline & & & \multirow[t]{2}{*}{ Pdp } & 285 & 183 & 200 & & & \\
\hline & & & & 619 & 367 & 349 & 17.1 & 4.2 & 2.1 \\
\hline & & \multirow{6}{*}{15} & \multirow{2}{*}{ Wen } & 250 & 232 & 232 & & & \\
\hline & & & & 972 & 906 & 887 & 44.3 & 11.4 & 5.7 \\
\hline & & & \multirow[t]{2}{*}{ Dpdp } & 288 & 206 & 284 & & & \\
\hline & & & & 430 & 285 & 306 & 10.4 & 3.0 & 1.5 \\
\hline & & & \multirow[t]{2}{*}{ Pdp } & 229 & 175 & 203 & & & \\
\hline & & & & 629 & 470 & 460 & 20.2 & 5.1 & 2.5 \\
\hline
\end{tabular}

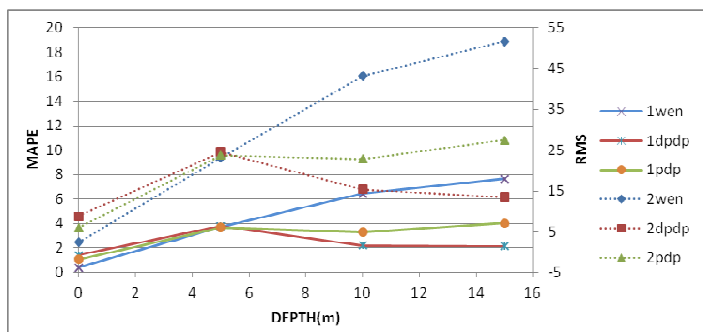

Fig 3a:Plot of misfit errors (1 - RMS, 2- MAPE) against depth for different electrode array using model 1

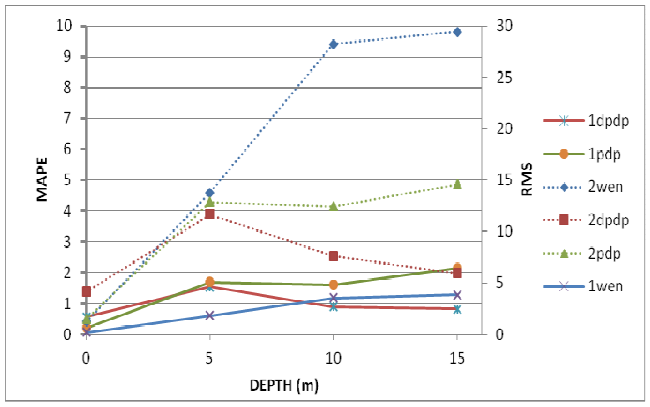

Fig 3b: Plot of misfit errors (1 - RMS, 2- MAPE) against depth for different electrode array using model 2

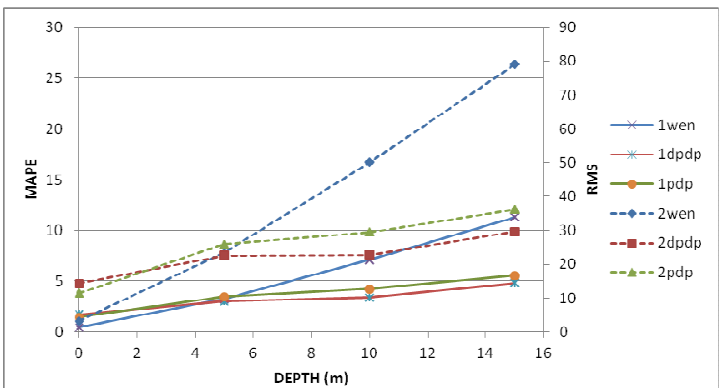

Fig 3c: Plot of misfit errors (1 - RMS, 2- MAPE) against depth for different electrode array using model 3

The field inversion results (Fig.4) reveal fractured zone width having $15 \mathrm{~m}$ width at $20 \mathrm{~m}$ depth in all the investigated arrays - Wenner, Dipole-Dipole and Pole-Dipole and this agrees well with the results of the numerical modelling. However, in Fig. 5, field inversion results show fractured zone of about $20 \mathrm{~m}$ width at $45 \mathrm{~m}$ depth on Dipole Dipole and Pole Dipole arrays but not evident in Wenner arrays. If the use of different arrays were not employed, the interpretation would have been erroneous. The absent of fractured zone on the Wenner pseudosection in Fig. 5 can be attributed to the vertical/slightly dipping structure of the fractured zone. Pole-Dipole produces a syncline bedrock depression unlike hollow-like 
fractured produced by Dipole- Dipole. This also validates its corresponding simulated result at this depth that Pole - Dipole cannot be considered very reliable for fracture imaging. This observation about the Pole-Dipole array may be due to interference from the remote electrode array and this effect may be suppressed by the reverse method. This confirms the results of earlier studies (Perren, 2005) where the Wenner array has been said to be insensitive to vertical structure unlike Dipole-Dipole which has
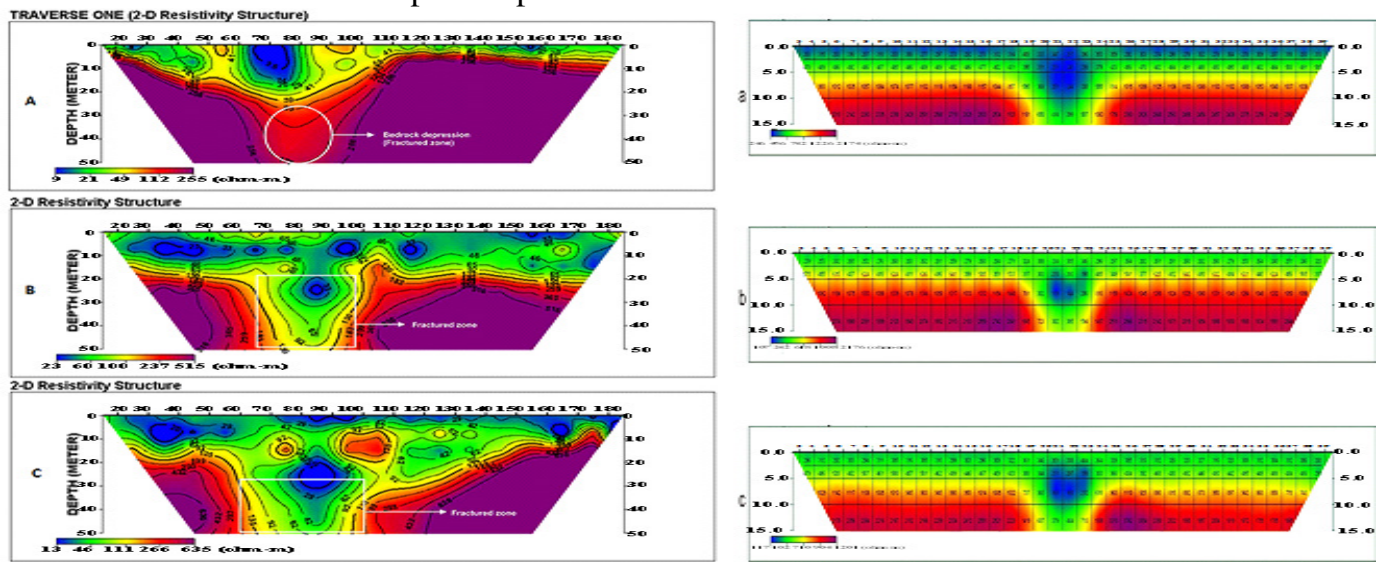

Fig 4: 2-D resistivity structure from field data and theoretical response of a fractured zone with $200 \Omega \mathrm{m}$ placed at $10 \mathrm{~m}$ depth along traverse 1 using (a) Wenner (b) Dipole-Dipole (c) Pole-Dipole arrays
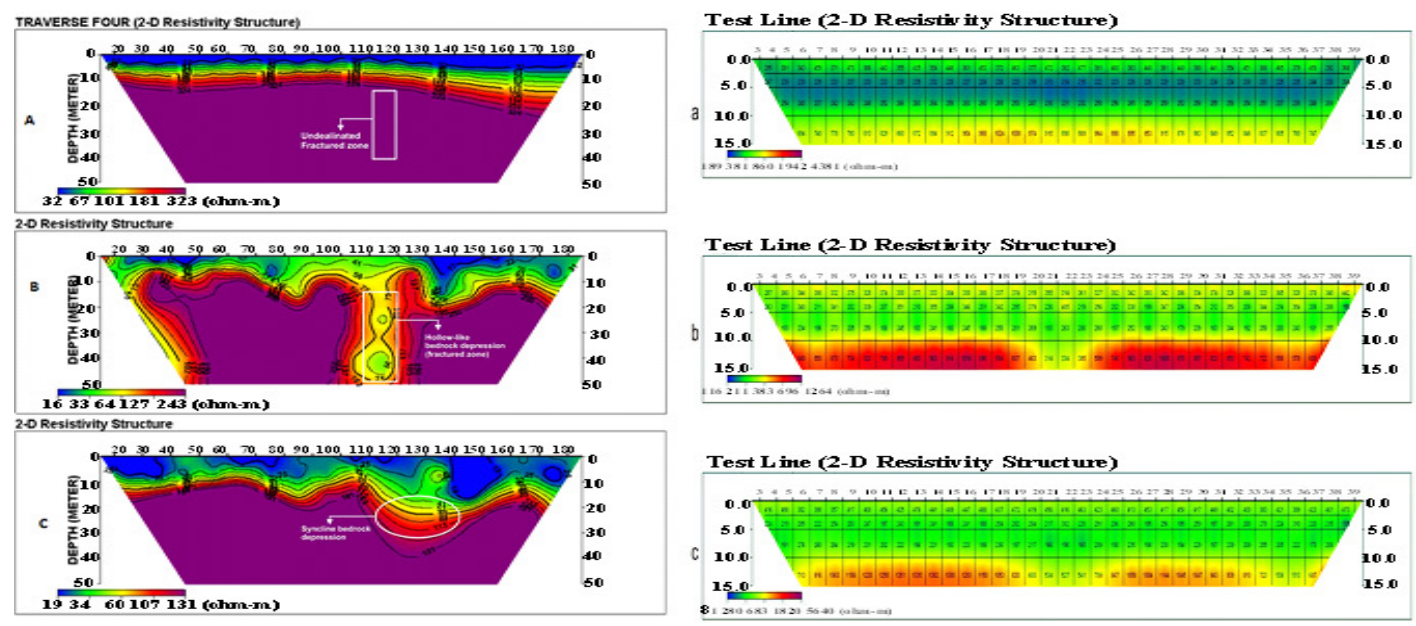

Fig 5: 2-D inverted model from field data and theoretical response of a fractured zone with $200 \Omega \mathrm{m}$ placed at $15 \mathrm{~m}$ depth along traverse 4 using (a) Wenner (b) Dipole-Dipole (c) Pole-Dipole arrays

Conclusions: This paper investigated the resolution capacity of three electrode configurations - the Wenner, dipole- dipole and pole-dipole at imaging fractured zone of different resistivity, thicknesses and depth of burial. The resolution capacity of the electrode arrays was determined in terms of the model misfit errors. Generally, the true resistivity values of the models were fairly reconstructed and underestimated. The importance of numerical simulation for survey design and planning prior to field data acquisition has been underscored in this study as time and cost will be minimized.

Acknowledgments: The authors wish to express their sincere appreciation to Tertiary Educational Fund (Tetfund) for funding this research and the University of Lagos, Nigeria for creating an enabling environment to conduct the research. Also, we are grateful to the anonymous reviewers for their useful criticism which has improved this manuscript. 


\section{REFERENCES}

Ajeigbe, OM; Adeniran, OJ; Babalola, OA (2014). Mineral Prospecting Potentials of Osun State. European Journal of Business and Management. 6(2): 115-123.

Alagbe, OA; Sunmonu, LA; Adabanija, MA (2013). Fracture distribution within Bowen University permanent site and its Hydrogeologic Implication. Res. J. of Physical Sci. 1(30): 1-5.

Francese, R; Mazzarin, F; Bistacchi, A; Morelli, G; Pasquarè, N; Praticelli, H; Robain, N; Wardell, W; Zaja, A (2009). A structural and geophysical approach to the study of fractured aquifers in the Scansano-Magliano in Toscana Ridge, Southern Tuscany, Italy. Hydrogeology Journal. 17: 1233 1246

George, A; Abong, AA; Obi, DA (2013). Fracture zone detection using very low frequency (VLF) electromagnetic method in part of Oban Massif Southeastern Nigeria. Adv. Appl. Sci. Res. 4 (6):104 $-121$.

Iloeje, NP (1976). A New Geography of Nigeria, Longman, London.

Ishola, KS; Nawawi, MNM; Abdullah, K; Sabri, AIA; Adiat, KA (2014). Assessment of the reliability of reproducing two-dimensional resistivity models using an image processing technique. Springerplus. 3: $1-12$.

Ojo, AO; Olorunfemi, MO (2013). Resistivity modelling of confined fractured basement column for varying thicknesses and depth of burial. Pac J. of Sci. and Technol. 14(1): 464 -475.

Loke, MH (1999). Electrical imaging surveys for environmental and engineering studies: A practical guide to 2D and 3D surveys http://www.geotomosoft.com/.

Okpoli, CC (2013). Sensitivity and resolution capacity of electrode configuration. Hindawi Int. J. of Geophys. Article ID 608037.

Olorunfemi, MO (2008).Voyage on the Skin of the Earth: A geophysical experience, Inaugural Lecture Series 211, Obafemi Awolowo University, Ile-Ife.
Perren, LJ (2005). Investigating the performance of electrical resistivity Array. MSc thesis, (Unpulished) Virginia Polytecnic Institute. USA.

Press, WH; Teukolsky, SA; Vetterling, WT; Flannery, BP (1996). Numerical Recipes in Fortran: The Art of Scientific Computing. Cambridge University Press, London, 192.

Rücker, C (2011). Advanced Electrical resistivity modelling and inversion using unstructured discretization. University of Leipzig $\mathrm{PhD}$ Dissertation.

Sandor, S; Attila, N; Laszlo, S (2011). Which geoelectric array sees the deepest in a noisy environment? depth of detectability value of multielectrode systems for various two-dimensional models. Journal of Physics and Chemistry of the Earth 36: 1398 -1404.

Sunmonu, LA; Alagbe, OA (2013). Ground magnetic study to locate buried faults: A case study of abandoned local government secretariat in Ogbomoso. Int. J. of Phys. 3(1): 70 - 75.

Szalai, S; Lemperger, I; Metwaly, M; Kis, A; Wesztergom, V; Szokoli, K; Novak, A (2014). Multiplication of the depth of detectability using gamma $\gamma 11 \mathrm{n}$ arrays. Journal of Applied Geophysics. 107: 195 - 206

Szalai, S; Lemperger, I; Metwaly, M; Kis, A; Wesztergom, V; Szokoli, K; Novák, A (2015). Increasing the effectiveness of electrical resistivity tomography using $\gamma_{11 n}$ configurations. Geophysical Prospecting. 63(2): 508 - 524.

Xianjin, Y; Lagmanson, MB (1999). Planning resistivity surveys using numerical simulations. Advanced Geosciences, Inc., Austin, Texas. 488 - 501.

Yi, M J; Kim, J H; Chung, S H (2003). Enhancing the resolving power of least squares inversion with active constraint balancing. Geophys. 68: 931 941.

Zienkiewicz, OC (1977). The Finite Element Method. Mcgraw-Hill, London. 